\title{
An overview of northern Vietnam deep crustal structures from integrated geophysical observations
}

\author{
Van-Toan Dinh ${ }^{1}$, Steven Harder ${ }^{2}$, Bor-Shouh Huang ${ }^{3, *}$, Viet-Bac Trinh ${ }^{1}$, Van-Tuyen Doan ${ }^{1}$, \\ Hop-Phong Lai ${ }^{1}$, Anh-Vu Tran ${ }^{1}$, Hong Quang-Thi Nguyen ${ }^{1}$, and Van-Duong Nguyen ${ }^{3,4}$ \\ ${ }^{I}$ Institute of Geological Sciences, Vietnam Academy of Science and Technology, Ha Noi, Vietnam \\ ${ }^{2}$ J.Miller Geophysical Laboratory, University of Texas at El Paso, TX, USA \\ ${ }^{3}$ Institute of Earth Sciences, Academia Sinica, Taipei City, Taiwan \\ ${ }^{4}$ Institute of Geophysics, Vietnam Academy of Science and Technology, Ha Noi, Vietnam
}

\section{Article history: \\ Received 2 February 2017 \\ Revised 4 December 2017 \\ Accepted 2 January 2018 \\ Keywords:}

Crustal structure, Red River fault Zone, Gravity inversion, Conrad, Moho, Northern Vietnam

Citation:

Dinh, V.-T., S. Harder, B.-S. Huang, V.-B. Trinh, V.-T. Doan, H.-P. Lai, A.-V. Tran, H. Q.-T. Nguyen, and V.-D. Nguyen, 2018: An overview of northern Vietnam deep crustal structures from integrated geophysical observations. Terr. Atmos. Ocean. Sci., 29,371-386, doi: $10.3319 /$ TAO.2018.01.02.01

\begin{abstract}
Multiple geophysical datasets from northern Vietnam were examined and reanalyzed to explore detailed structures within the deep crust and their relationship to major tectonic fault systems in this region. Deep seismic data using explosions were collected and examined to crustal structure in northern Vietnam. Based on the determined depths of seismic boundaries, we verified crustal densities by gravity inversion model of Bouguer anomalies. Then, refer to those verified crustal densities; crustal interface boundaries along selected profiles in northern Vietnam were inverted by fitting its gravity anomalies. Integration results reveal significant lateral variations in the depth of the Moho discontinuity. The Moho depth increases from coastal to mountainous areas, and increases more rapidly towards the northwest. The rapid thickening of the crust can be considered as the southeastern extension of the eastern Tibetan along the eastern Himalayan syntaxis. We deduce that these variations are controlled by the main tectonic faults in northern Vietnam. Furthermore, although the Red River fault zone is considered as a boundary between two regional crustal blocks, however, no remarkable differences in crustal density and Moho depth were obtained by our analysis. A comparison of previous magnetotelluric studies and heat-flow observations indicates that the low resistivity of the uppermost mantle beneath the Hanoi basin region is well correlated with the location of a high heat-flow anomaly. The high heat-flow and thin crust determined in this study is suggestive of a recent rifting process of the opening of the South China Sea.
\end{abstract}

\section{INTRODUCTION}

Northern Vietnam, which is not far from the intersection of three major plates (i.e., the Eurasian, Indo-Australian, and Pacific plates) and includes the southern segment of the regional strike-slip Red River fault, has experienced multiple episodes of geotectonic evolution (Fig. 1). According to the hypothesis of Southeast Asia extrusion, largescale left-lateral movement along the Red River Shear zone (RRSZ) during the Cenozoic, with clockwise rotation of the Indochina block, has with accompanied the collision between the Indo-Australian and Eurasian plates (Tapponnier et al. 1982, 1986). According to this model, the Red River

\footnotetext{
* Corresponding author

E-mail:hwbs@earth.sinica.edu.tw
}

strike-slip fault system cuts the entire lithosphere. However, based on the recognition that the crust has thickened during collision, a strike-slip fault can be activated to accommodate the thickening process. Such a strike-slip fault can be solely crustal in nature, and do not penetrate the lithosphere. This model is supported from a numerical investigation of large-scale continental deformation in the Indian-Asia collision zone (England and Houseman 1986). Thus, a crustal model has arisen contention to a lithospheric model. Studies on the tectonic environment and geological structures of the RRSZ support both a lithospheric model (Gilley et al. 2003; Leloup et al. 2007) and a crustal model (Jolivet et al. 2001; Searle 2006) of the Red River strike-slip fault system. Furthermore, the role of RRSZ on the opening of the South 
China Sea and the continental extrusion was debated according to new observations (Lee and Lawver 1995; Chung et al. 1997; Mazur et al. 2012).

The RRSZ divides northern Vietnam into two parts of relatively equal area. Its activity strongly affects presentday tectonic features, and thus represents the geodynamic regime in this area. Most of the main faults in northern Vietnam are strike-slip faults, showing left-lateral movements along NW-SE trending systems, and a reverse (right-lateral) sense of movement along orthogonal NE-SW and submeridian systems. These investigations are based on geotectonic and geomorphological observations of events and processes occurring since the Paleocene-Miocene (Tapponnier et al. 1986). However, present-day deformation caused by a plate collision represents reactivation of the Red River fault zone (RRFZ) (Tapponnier and Molnar 1977; Allen et al. 1984; Replumaz et al. 2001; Phan et al. 2012). Evidence of rightlateral motion since the Pliocene has been recorded along the Red River fault and along a series of NW-SE trending faults in northern Vietnam (Nguyen 1991; Nguyen et al. 1996; Vu 1996). Of course, left-lateral motion has been detected on various submeridian and NE-SW trending fault segments (Tran and Van 1996, 2006). Most of these Cenozoic faults are still active at the present time, and represent the geodynamic response of the region to local and regional stress regimes (Nguyen 1996a; Nguyen and Hoang 2001).

On a regional scale, northern Vietnam is separated into two geological regions by the NW-SE trending RRFZ. The southwestern region (referred to as the Southwest region in this study) belongs to the pre-Cenozoic Indochina block and the northeast region (hereafter, the Northeast region) is part of the South China block. The structural characteristics of the two regions are different. In the Northeast region, arc-shaped tectonic faults are well developed, showing predominantly submeridian trends in the north and subparallel trends in the south (Bui 1982; Tran et al. 2008). In contrast, most of the main tectonic faults in the Southwest region are predominantly NW-SE trending extensional structures. The section of the RRFZ in northern Vietnam is sliding in this NW-SE direction, and activity is confined to two subparallel branches of the fault: the southwestern Red River and the northeastern Song Chay faults (Fig. 2).

Information about deep crustal structures in northern Vietnam is necessary to understand the geodynamic evolution of the region and the regional consequences of collision between the Indo-Australian and Eurasian plates. In the past, investigations of crustal structure in northern Vietnam have relied mainly on gravity data (Bui 1983; Cao 1985; Cao and Dinh 1999; Dang 2003). However, uncertainties in crustal parameters have resulted in large variations of results from different studies (Dinh et al. 2009). In particular, the crustal density, which is a critical parameter for the interpretation of gravity data, is not well constrained in this region. Therefore, we attempt to address this difficulty in this study. Based on gravity modeling, the geophysical observations from this and all previous studies were integrated so as to thoroughly investigate the deep crustal structures of northern Vietnam. We further discuss the implications of this crustal model for regional geodynamics, as well as for geotectonic hazard assessment, and discuss the implications for future research on the RRSZ.

\section{REVIEW OF GEOPHYSICAL INVESTIGATIONS OF DEEP CRUSTAL STRUCTURES IN NORTHERN VIETNAM}

Since 1955 , and especially after 1960, geophysical investigations have been conducted as a part of geological surveys and mineral exploration in Vietnam. Initially, activities focused on mineral exploration and were confined to areas of mining activity. Most of these activities employed geoelectric and magnetic surveys to focus on coal mining areas in the Northeast region of Vietnam. Gravity survey was also conducted in the Cenozoic Hanoi basin. Maps of the entire basin were compiled at a scale of 1:100000, and at larger scales for some regions of the basin. Some magnetotelluric profiles across the RRFZ were also constructed. At the same time, for the purpose of oil exploration, intensive gravity and geoelectrical investigations were conducted in the Anchau region, located in a Mesozoic basin approximately $100 \mathrm{~km}$ to the northeast of the Hanoi basin. The above geophysical investigations have revealed structures within the uppermost sections of these two basins. Later, during the period from 1965 - 1975, extensive geophysical investigations were conducted in the Cenozoic Hanoi basin for the purpose of oil exploration. Among them, several surveys employed two-dimensional (2D) seismic reflection techniques over distances on the order of $1000 \mathrm{~km}$, and seismic refraction techniques over distances of hundreds of kilometers. The seismic reflection data provided reflected signals from crustal interfaces at depths greater than $2 \mathrm{~km}$. The refraction data provided information on seismic velocities of crustal layers to depths of approximately $5 \mathrm{~km}$. However, in many locations within the basin, the seismic profiles did not extend to pre-Cenozoic basement. Since 1976 (post-reunification of Vietnam), more intensive surveys and geophysical investigations have been conducted, both onshore and offshore. As of 1980, a map of Bouguer gravity anomalies has been available at a scale of 1:500000, and aeromagnetic surveys have been available at a scale of 1:200000; these surveys cover most of the territory of Vietnam (Department of Geology and Minerals of Vietnam 1995). At limited locations in northern Vietnam, some magnetotelluric and geothermal profiling has also been performed (Pham et al. 1995; Nguyen 1996b; Doan et al. 2001; Doan and Dinh 2003; Le et al. 2008, 2009).

Several geophysical surveys were conducted in northern Vietnam, mainly during the early stages of mineral and 


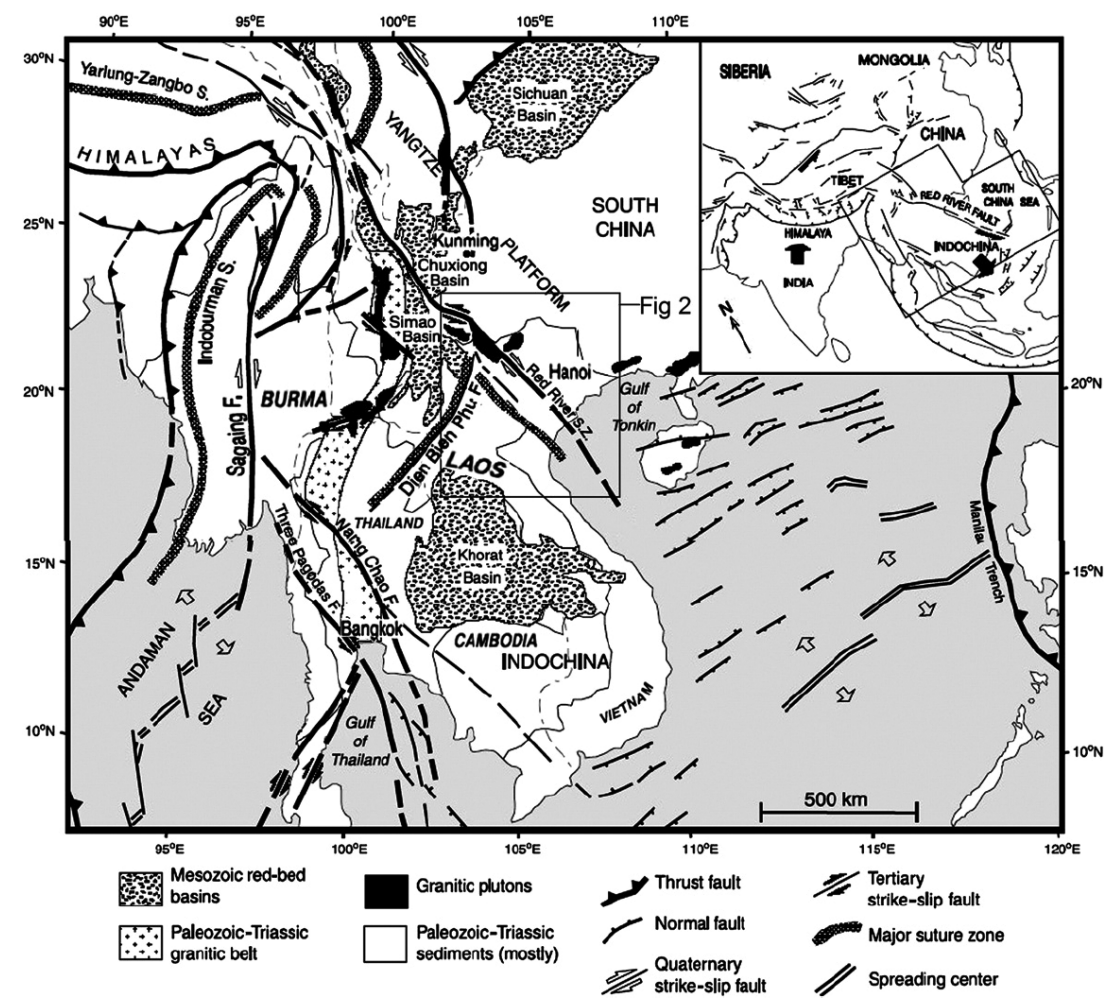

Fig. 1. Simplified Geological and tectonic map of Southeast Asia. Modified from Leloup et al. (1995) and Phan et al. (2012). The square indicates the area shown in Fig. 2 (i.e., the study region in northern Vietnam).

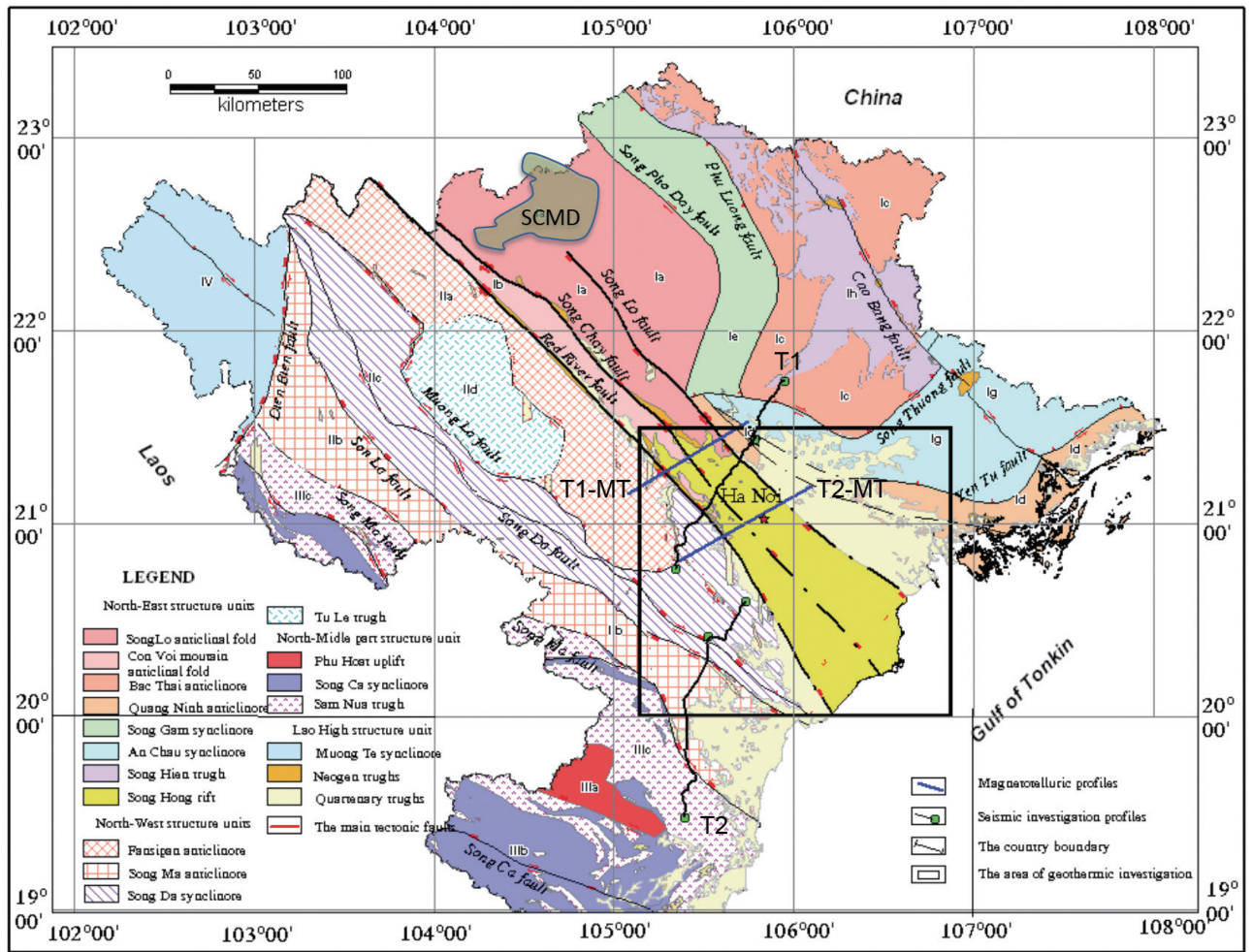

Fig. 2. Map of active faults and geological structures in northern Vietnam and surrounding countries (modified from Dinh 2010). Thick and thin black lines represent major and minor active faults, respectively. Blue lines indicate the magnetotelluric (MT) investigation lines across the RRFZ. Black dashed lines indicate the northern (T1) and southern (T2) deep seismic explosion lines. Green circles indicate seismic explosion shot locations. The Song Chay Metamorphic Dome (SCMD) is drawn as an isolated block. The square indicates the area of heat flow surveyed and mapped by Dinh et al. (1994); Fig. 4 shows details of this area. 
oil exploration. Unfortunately, many observations, analyses, and reports on the deep crust and tectonic evolution of the area have been published only in Vietnamese, and their availability is limited. Furthermore, results analyzed using different datasets from different authors present a variety of uncertainties related to methodology and interpretation. Until now, no careful examinations or discussions of early observations have been available. Thus, reexamination of early data on deep crustal structures, including careful evaluations of the observations and methods used in previous investigations, is necessary. In this study, we reexamine and analyze earlier geophysical observations and provide a consistent overview of their contribution to the understanding of deep crustal structures beneath northern Vietnam. We first review individual datasets, and then integrate these datasets to enable an examination and analysis of recently obtained data on deep crustal structures.

\subsection{Magnetotelluric Investigations of the Red River Fault Zone}

During 1996 - 1997, a framework was developed for collaboration between researchers at the Institute of Geological Sciences, Vietnam Academy of Science and Technology, and the Institute of Earth Physics, Strasbourg, France. The joint research program analyzed two magnetotelluric (MT) profiles across the RRFZ, referred to as T1-MT and T2-MT (Fig. 2). Two pairs of electrical and magnetic field recordings were obtained during this survey. Since two profiles were across the same the Red River fault zone with the distance between them is just about $40 \mathrm{~km}$ and the presented feature of the apparent resistivity and 2D resistivity structures are similar in both profiles (Doan et al. 2001). In this study, a 2D inversion was applied to determine the $2 \mathrm{D}$ resistivity structures from recordings of T2-MT only (Fig. 3). According to the resistivity structure model obtained from 2D inversion, the horizontal boundary separating regions of low and high resistivity occurs at depths of $28-32 \mathrm{~km}$. This boundary, which is present along most of the T2-MT profile, was considered to represent the Moho interface (Doan et al. 2001). Much greater heterogeneity in resistivity values was detected in the deep crust layer as compared with values in upper layers. In the southwestern half section of this profile, resistivity in the surface layer was generally less than $500 \mathrm{Ohmm}$. The bottom of this layer, which varies from 1 - $4 \mathrm{~km}$, is consistent with the top of crystalline basement, as revealed by other geophysical studies (Dinh et al. 2009; Dinh 2010). In the northeastern half of the profile, from $48 \mathrm{~km}$ to the northeastern end of the profile, the low-resistivity subsurface layer was absent. The observed high resistivity from the surface to the deep crust in this section is characteristic of well-consolidated rocks in the Northeast region. A high shear-wave velocity obtained from a surface wave dispersion analysis confirmed the stable state of the crustal structure in the Northeast region (Wu et al. 2004).

Along profile T2-MT, the region from $13-27 \mathrm{~km}$ showed a very-low-resistivity top layer and extending to a depth of greater than $10 \mathrm{~km}$ (Fig. 3). Beneath that, a low resistivity values (less than $200 \mathrm{Ohmm}$ ) were found. This region delimited by the Red River fault in the southwest and the Song Chay fault in the northeast was defined as the RRSZ. It is found that abnormally low resistivities in this section, as compared with surrounding areas, extended to the deep crust (Fig. 3). However, the low resistivity detected under point LAS at the northeast end of the profile was considered to the result from conditions similar to those in the RRSZ section of the arc-shaped subparallel Dong Trieu fault (Fig. 4).

\subsection{Geothermal Investigations in the Hanoi Basin}

Results of geothermal investigations are available for limited areas of northern Vietnam (Duchkov et al. 1992; Dinh et al. 1994; Harder et al. 1995; Doan et al. 2010). Heat flow was measured at depth within boreholes in the temperature-stable zone, which is estimated to be deeper than 12 - $15 \mathrm{~m}$ in the Hanoi region (Doan et al. 2010). A concentrated area of geothermal measurements is available from the Hanoi basin area (square box in Fig. 2), where a network of geohydrologic monitoring wells and a series of oil exploration boreholes were used for measurements. Heat-flow values were obtained in 31 shallow geohydrologic wells (depths within $30-160 \mathrm{~m}$ ) and in 17 deep oil-exploration boreholes with depths from $300-3300 \mathrm{~m}$ (Dinh et al. 1994). The geothermal investigations in this area were conducted for the purpose of detecting heat flow related to upwelling mantle and for measuring the temperature structure of the crust (Fig. 4). A region of high temperature gradients is located in the southeastern part of the Hanoi Basin. Two areas of high heat-flow anomalies were observed. The first, with heat-flow values of greater than $90 \mathrm{mWm}^{-2}$, occupies an elliptical area approximately $40 \mathrm{~km}$ long, located between the Red River and Vinh Ninh faults (Fig. 4); its northwest extension approaches a section of abnormally low resistivity in the RRSZ (detected by the T2-MT profile, Fig. 4). Within the central section of the anomaly, heat-flow values are greater than $110 \mathrm{mWm}^{-2}$. In the northeastern part of the basin, a second anomaly with heat-flow values exceeding $90 \mathrm{mWm}^{-2}$ was observed in coastal areas along the Song Lo fault. The main part of the anomaly may extend to offshore areas. Along the northern margin of the basin, a smaller heat-flow anomaly was detected, with heat-flow values exceeding $70 \mathrm{mWm}^{-2}$. This anomaly, which extends along the northeastern edge of the Song Lo fault, is approximately 20 $\mathrm{km}$ long. Thus, heat flow in the area of the Hanoi Basin is generally high, and the locations of heat-flow anomalies were proposed to correspond to the locations of Cenozoic rifting structures in the basin by Dinh et al. (1994). 


\subsection{Deep Seismic Surveys Across Major Tectonic Faults in Northern Vietnam}

Wide-angle reflection and refraction seismic profile provides information for delineating structural and tectonic features in the deep crust. However, the high cost of such surveys and the complexity of operations in densely populated areas have prevented its application in Vietnam. During 2007 - 2008, in a cooperative study between researchers at the W. J. Miller Geophysical Laboratory at the University of Texas at El Paso (USA) and the Institute of Geological Sciences, Vietnam Academy of Science and Technology (Vietnam), the first wide-angle reflection/refraction inves- tigations were conducted in northern Vietnam along two short profiles (approximately $130 \mathrm{~km}$ ) (Fig. 2). Both profiles were designed to intersect the main structural units in the region (Harder and Dinh 2011).

The wide-angle reflection/refraction data were previously analyzed and two crustal structure sections were constructed (Dinh et al. 2009, 2010, 2011). The first profile intersected a number of arc-shaped faults belonging to the Northeast structural region including the Song Lo fault and branches of the RRFZ (Fig. 2). The second profile crossed most of the main systems of tectonic faults in the Northwest structural region, such as the Song $\mathrm{Da}$, Son La, and Song Ma fault systems. Each of the profiles consisted of six

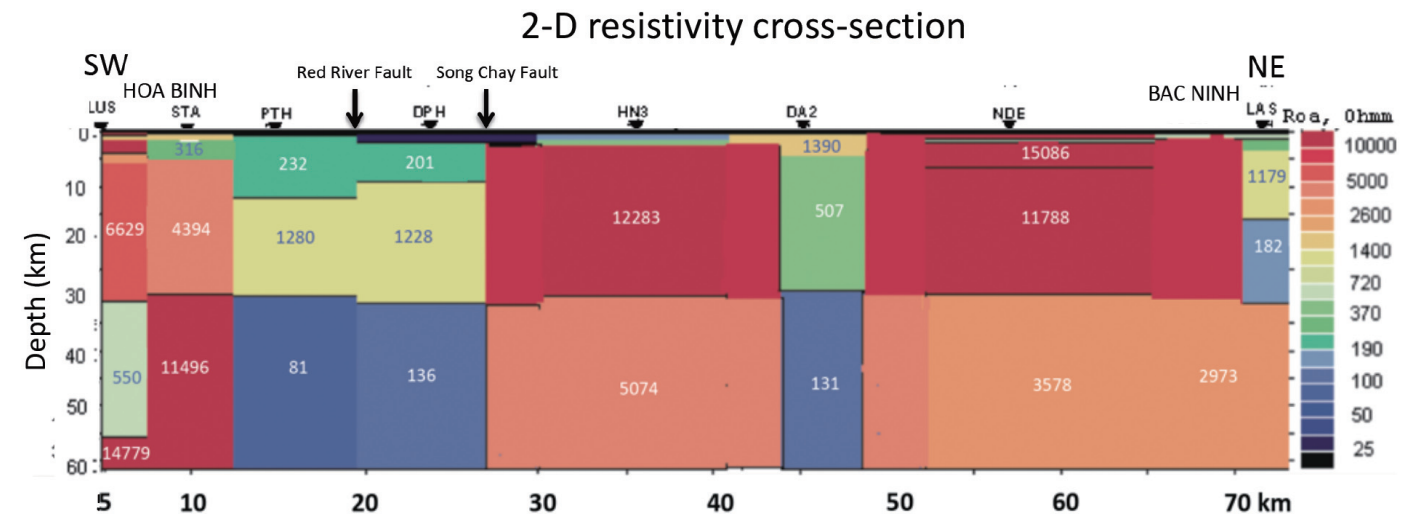

Fig. 3. The inverted 2D resistivity cross-section (profile T2-MT of Fig. 2.) from magnetotelluric survey across the Red River fault zone (modified from Doan et al. 2001). The Inverted filled triangles at the ground surface of indicate the locations of the eight MT measurement points. The locations of the Song Chay fault and the Red River fault across this profile are indicated by arrows at top.

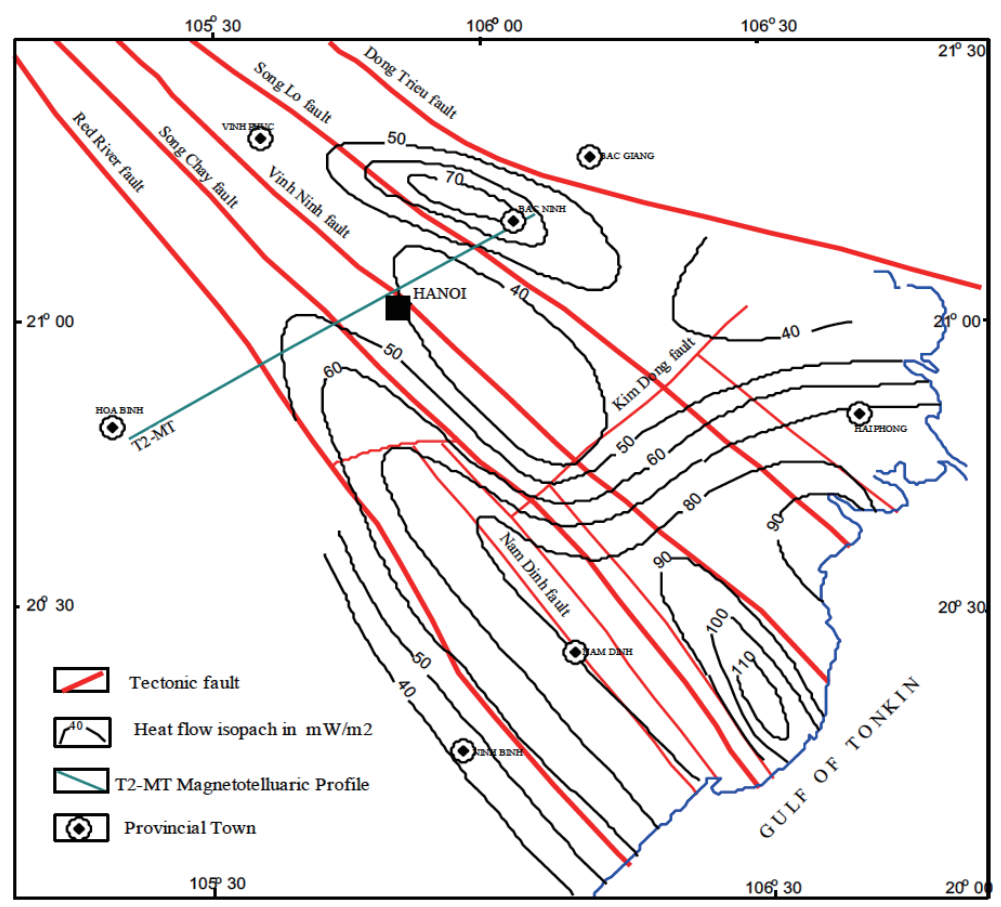

Fig. 4. Heat-flow isopachs in the Hanoi basin (modified from Dinh et al. 1994). Symbol black squire is the reference location of Hanoi. 
shots fired at three locations. Because the seismic signals were generated by relatively small shots, the crust-mantle reflection was not visible in the raw data on all traces. The reflection signals were more clearly observed after data processing with band-pass filtering in the frequency range 1 - $20 \mathrm{~Hz}$. Among the six seismic sections produced by the explosions from the six locations, four sections provided reflection arrival times related to the Moho (Dinh et al. 2011). The wide-angle reflection/refraction signals could be seen on section generated by a single explosion (Fig. 5). However, it was enhanced by a summation of the two shots at each location. A simple 1D seismic model was employed in the processing of data from northern profile $\mathrm{T} 1$ based on the wave-field Tau-P analysis (McMechan et al. 1982), yielding an estimated crustal thickness of approximately $27 \mathrm{~km}$ in the margin of the Hanoi Basin (Dinh et al. 2009; Harder and Dinh 2011). The $1 D$ estimates were taken as input for $2 D$ forward modeling using the ray tracing program RAYINVR (Zelt and Smith 1992) in an iterative procedure starting with the shallow structure and the upper crust, and then including the Moho reflections in order to model the whole crust. The determined velocity model of the northern seismic profile (T1) inverted from three seismic sections of different shot points as shown in Fig. 6 (Dinh et al. 2011).

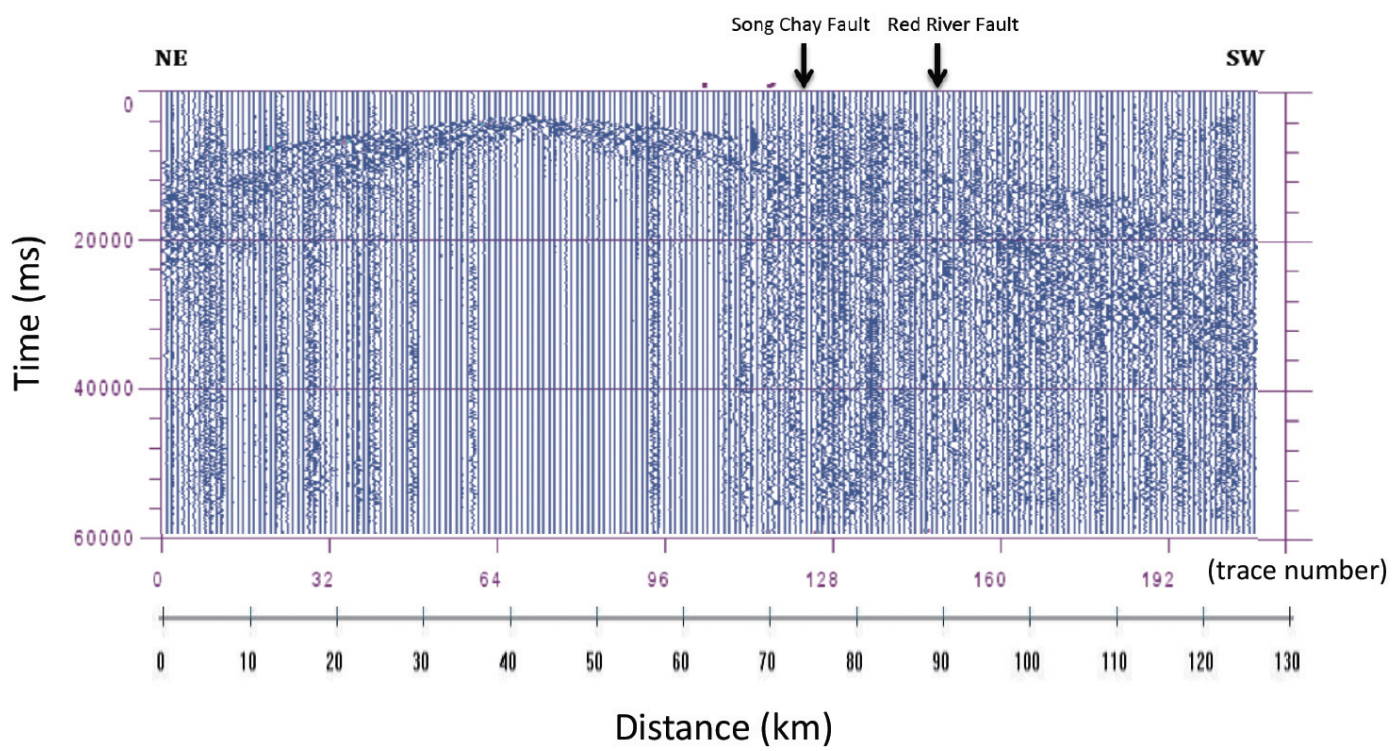

Fig. 5. Unreduced seismic section from the middle explosion shot point of the northern profile (profile T1). This section is plotted on the basis of trace numbers from the northeastern end of the profile. The locations of the Song Chay fault and the Red River fault across this profile (Fig. 4) are indicated by arrows at top.

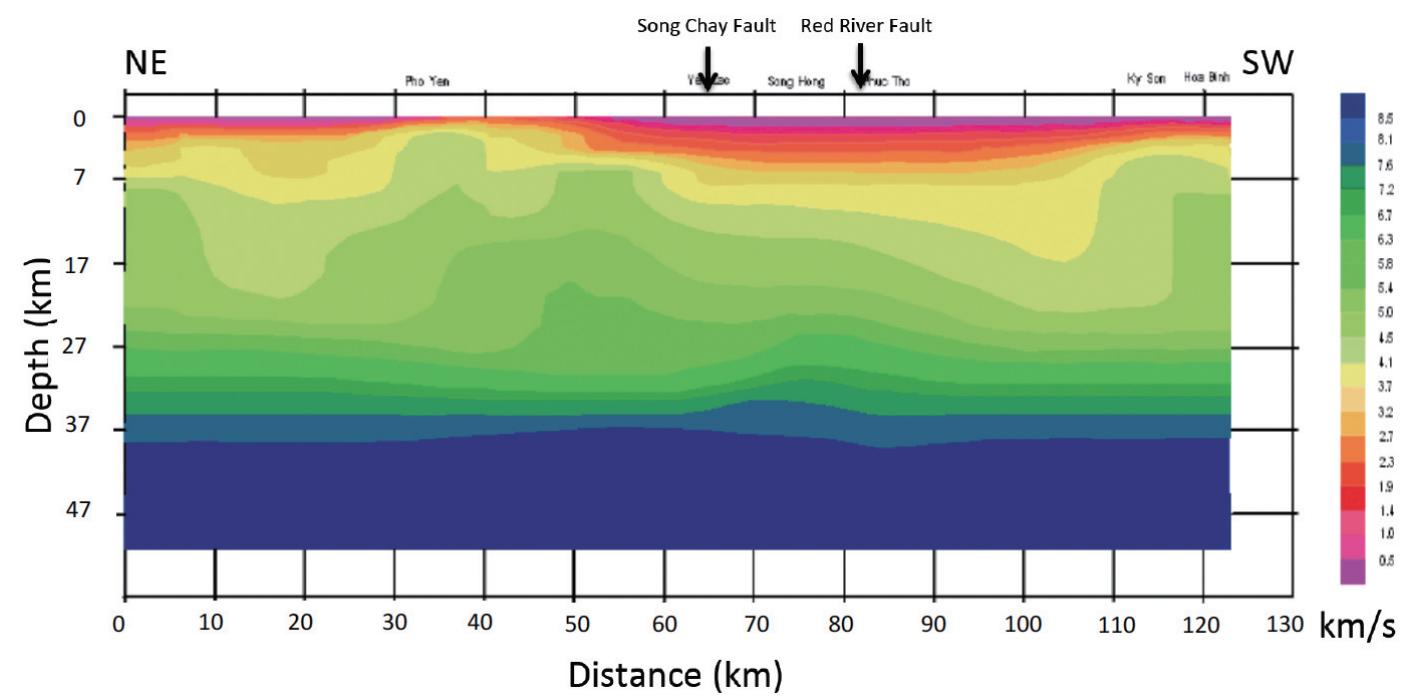

Fig. 6. Determined velocity model of the northern seismic profile (T1) from a 2D seismic travel time inversion analysis (modified from Dinh et al. 2011). The deepest interface of this $2 \mathrm{D}$ velocity model is suggested by Dinh et al. (2011) as the Moho interface. 


\subsection{Regional Gravity Investigations in Northern Vietnam}

Until recently, most geophysical data available for northern Vietnam consisted of gravity and magnetic anomaly maps (Department of Geology and Minerals of Vietnam 1995; Doan et al. 2001). In this study, based on collected data, 18 gravity lines (Fig. 7) uniformly distributed across northern Vietnam, were reprocessed for the regional Bouguer gravity map to determine subsurface crustal structure profiles. Patterns of obtained Bouguer gravity anomalies indicate that the Northeast region is characterized by relatively simple subsurface structures (Fig. 7). The eastern part of this region is dominated by a smooth regional anomaly trending in a NE-SW direction. On the northwestern corner of this region, the regional gravity anomalies change to a predominantly NW-SE direction, and the horizontal gradients in size and intensity of the anomalies are more strongly developed. Within the RRFZ, there exist a number of narrow NW-SE trending gravity anomalies. A negative gravity anomaly with strong horizontal gradients is present in the area of the Hanoi basin, where crustal thicknesses are estimated to be thinner than those in other areas (smaller than $26 \mathrm{~km}$ ) (Dinh et al. 2011).

Over the years, interpretations regarding deep structures in northern Vietnam have been based mainly on the distribution of gravity anomalies, as most of the main struc- tural elements of northern Vietnam are reflected in the gravity data (Bui 1983; Cao 1985; Cao and Dinh 1999; Dang 2003). However, uncertainties and differences regarding the results and interpretations of different researchers can be attributed to large differences in the values of crustal parameters used in the different studies, as the values of these parameters have not been well constrained.

\section{ANALYSIS AND RESULTS}

In this study, we inverted gravity data to reconstruct the crustal structure interfaces for the entire region of northern Vietnam. Our analysis procedure was performed in two steps. First, we compiled two seismic explosion datasets that intersect the major geotectonic units of northern Vietnam and all previously available geophysical information to infer depths of the major crustal interfaces beneath the two seismic profiles. From these data, two crustal profiles with 2D interfaces were reconstructed. Then, we fitted the Bouguer gravity anomalies along each profile to determine the densities of crust beneath profile. Second, by constraining the range of possible crustal densities as well as additional surface-layer sediment densities determined by the Vietnam Geological Survey, we reconstructed 18 crustal profiles from the inversion of gravity data so as to determine the depths of the Moho and Conrad discontinuity (referred to as the Moho and Conrad in this study). We then integrated

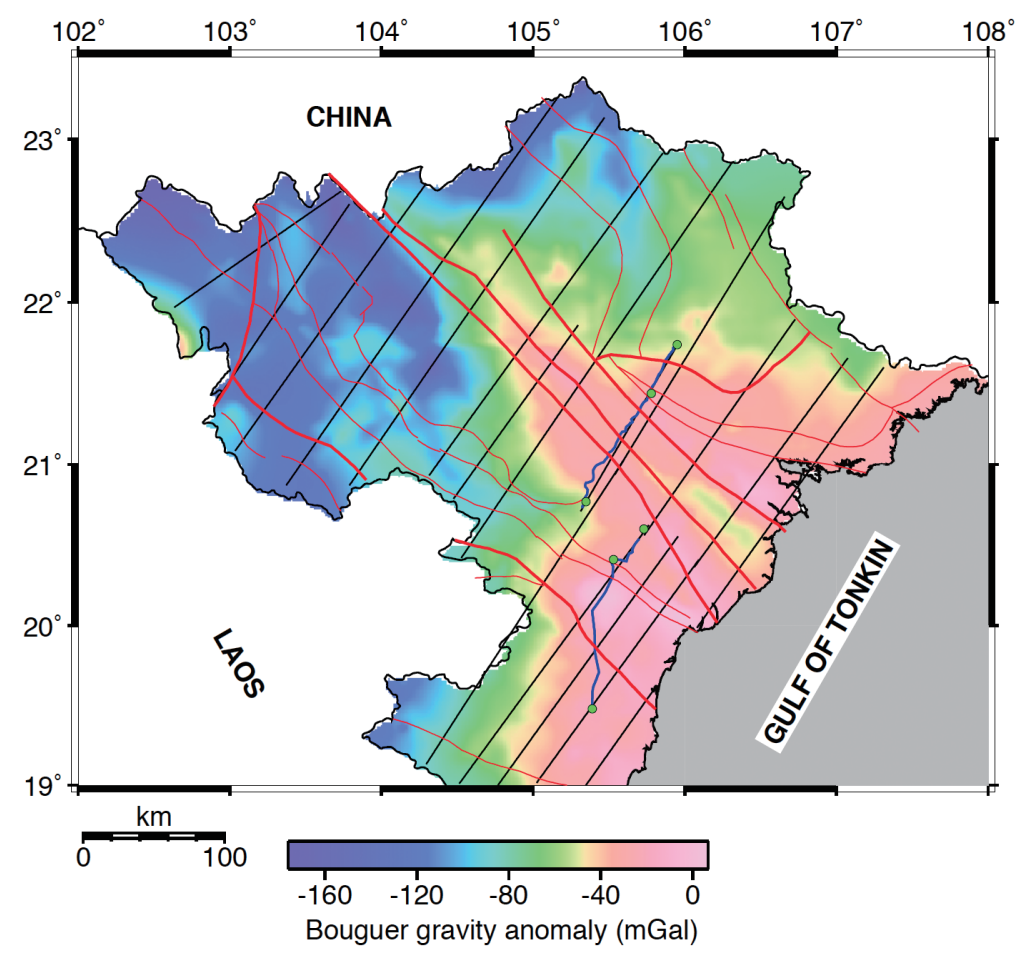

Fig. 7. Bouguer gravity anomaly map over northern Vietnam (a color scale is at the bottom of the map). Blue lines indicate the northern and southern deep seismic explosion lines, and green circles indicate the locations of seismic explosion shot points. Black solid lines indicate the locations of gravity lines selected in this study to invert crustal structure profiles. Thick and thin red lines indicate major and minor active faults, respectively. 
the crustal profiles to reconstruct the crustal structures of the entire northern Vietnam region.

\subsection{Crustal Densities Along Deep Seismic Survey Profiles}

We reconstructed crustal structure section beneath seismic profile, based on the seismic velocity model and combined with the results of additional gravity and geological data related to tectonic fault systems nearby. The structures of both sections are similar to those obtained from the seismic profiles, with limited modifications and smoothing to fit geological data. For example, the section in Fig. 8 was modified from the seismic profile presented in Fig. 6. In the reconstructed section, the depths to the uppermost interface and crystalline basement were estimated from additional geophysical and geological information (Bui 1983; Doan et al. 2001; Dinh et al. 2011). Thus, on the northern seismic profile (T1 in Fig. 2), the depth to crystalline basement varied from smaller than $1 \mathrm{~km}$ to larger than $6 \mathrm{~km}$. The high uplifted block on the northeast side of the Song Lo fault zone is related to the shallow depth of the basement [thus, smaller than $1 \mathrm{~km}$ beneath the southwestern (SW) explosion point, Fig. 6]. The thickest section of Cenozoic sediment (deeper than $6 \mathrm{~km}$ ) is located between the Red River and Song Chay faults. After these thinner sedimentary modifications to the original seismic profile, the reconstructed section (Fig. 8) shows the main crustal interfaces between the surface and the upper mantle. The major surface faults were plotted as reference from its surface locations and extend to the deep crust according to information of fault orientations (Dinh et al. 2011). Based on the seismic velocity model of the southern profile (T2), not shown in this study, similar procedure has been applied to reconstructed structural section of T2 (Fig. 9).

In this study, the reconstructed sections (Figs. 8 and 9), in combination with gravity data modeling, were used to constrain the densities of the Earth's crust. Of course, the density values of the uppermost sedimentary layers in northern Vietnam are strongly lateral variation and depend on rock type as well as the degree of deformation and weathering. Table 1 presents the average density values for the uppermost sedimentary layers inferred from density measurements of different sedimentary rocks, as performed by the Vietnam Geological Survey (Bui 1986). In Fig. 10, the density value of the uppermost sedimentary layer was previously assigned based on its surface rock types and was used in the gravity computations in this study. Based on the interface structure along profile T1 (Fig. 8), the density values of deep crust were determined by fitting observed gravity anomalies from a computation using the 2.5D gravity modeling (Busby 1987) and as shown in Fig. 10. The major surface faults were plotted as reference in Fig. 10 and did not involve determining crustal densities. Because the densities of the deep crustal layers and mantle reflect the regional character of the struc- ture model, the values obtained from the above calculations were used to reconstruct a crustal model for gravity modeling of areas outside the seismic profiles. The determined crustal densities of the upper crust, lower crust and mantle were listed in Table 1 also.

\subsection{Regional Crustal Structures of Northern Vietnam}

For the construction of the initial gravity model, we referenced average density values of the uppermost sedimentary layer listed in Table 1. The theoretical gravity anomalies from the crustal structures were calculated by forward modeling, in which the geometric form of each layer was approximated by a polygonal set (Won and Bevis 1987). The lengths of gravity bodies in a direction perpendicular to the investigated profile were estimated directly from the map by measuring the length of the anomaly in this direction. To minimize the deviation between theoretical and observed anomalies, the Marquardt least-squares method was applied to the gravity inversion (Thanassoulas et al. 1987). A fit between the calculated and observed curves is difficult to obtain, as the original Bouguer gravity anomalies contain numerous small local anomalies. The testing calculations conducted for profiles along the two sections indicated a better fit to the data when using an upward-continuation of gravity anomalies to above-surface level of $2.5 \mathrm{~km}$ (Dinh et al. 2010). Elimination of a small number of local anomalies related to shallow subsurface objects and the upward-continuation to a level of $2.5 \mathrm{~km}$ did not generally distort the relationship between the observed Bouguer anomalies and the structural elements; thus, this mapping was used for the gravity modeling in this study.

The depths to the Moho obtained from the two MT profiles were used to constrain the model geometry and parameters used in the gravity modeling along the profiles (Doan et al. 2001; Doan and Dinh 2003). According to the regional density parameters listed in Table 1, observations along each gravity line were inverted to derive the depths of crustal interfaces by theoretical gravity modeling (Won and Bevis 1987). Finally, we integrated the crustal structure profiles to derive a crustal structure model for the region of northern Vietnam.

The depths to the Moho in northern Vietnam, as obtained by our calculations, are presented in Fig. 11. The depth to the Moho changes gradually, increasing from 27 - $30 \mathrm{~km}$ near the coast to $36-37 \mathrm{~km}$ at the Vietnam-China border. The uplifted portion of the block also extends in a northeast direction, with the depth increasing to larger than $33 \mathrm{~km}$ in the area close to the Vietnam-China border. In the northern parts of this region, the depression of the Moho surface extends to the region of China, with depths larger than $36 \mathrm{~km}$ in the center of the northern region. We also found that the depth of the Moho gently increases from coastal areas to the northwest section of the fault zone, reaching 


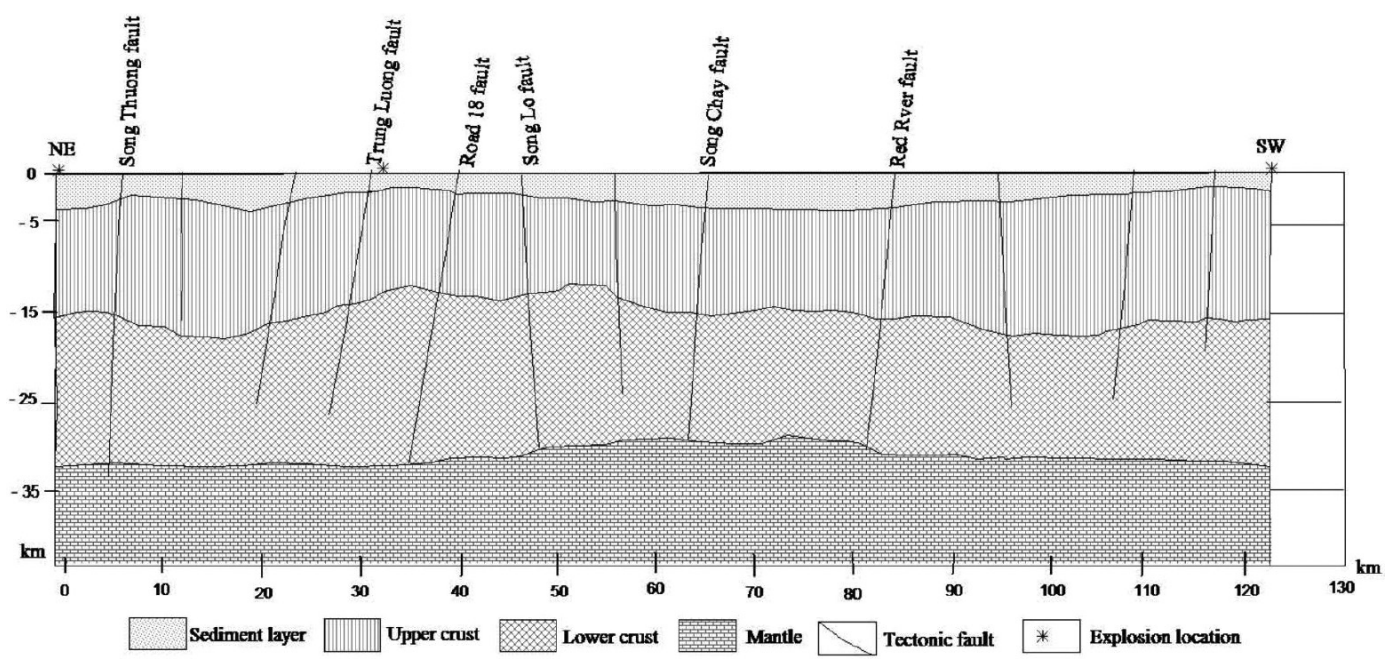

Fig. 8. Crustal structural model modified from the determined seismic velocity model of the northern seismic profile T1 (Fig. 6). Symbol start indicated location of explosion.

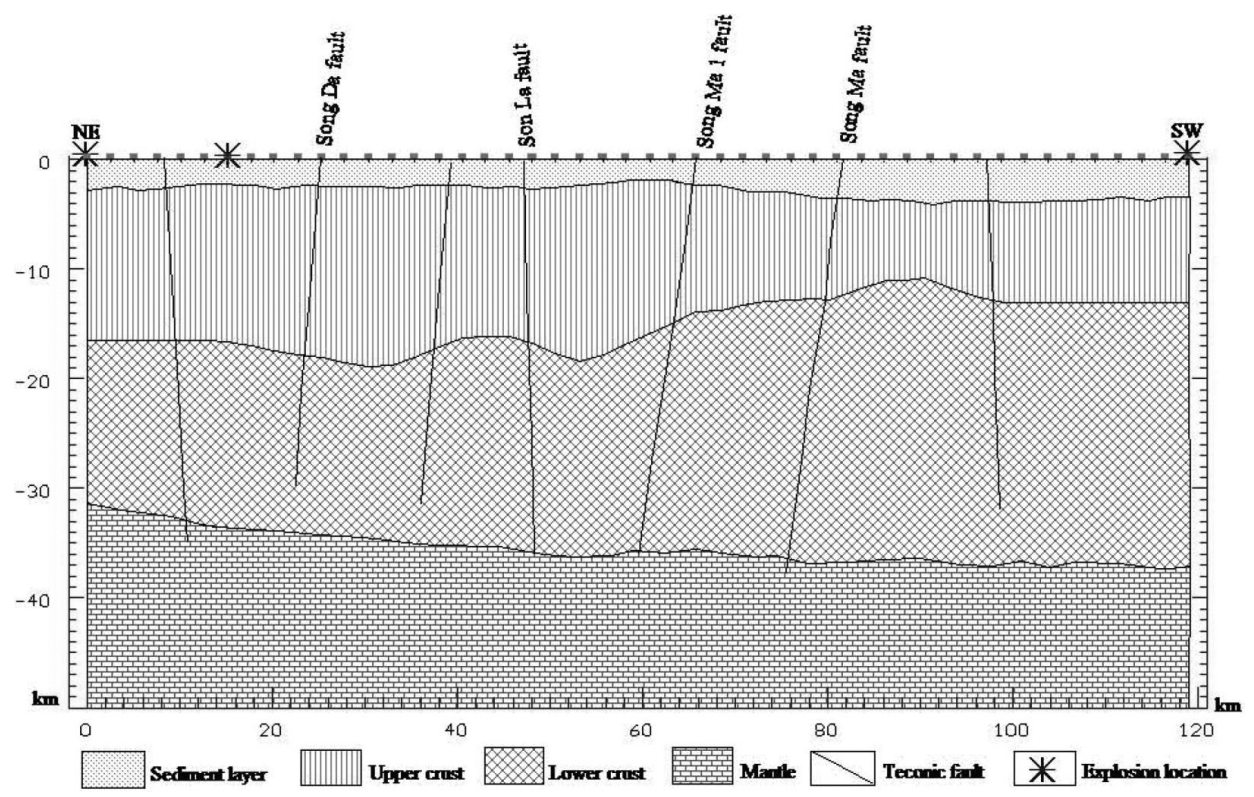

Fig. 9. Determined crustal structural model for the southern seismic profile T2 (modified from the seismic velocity model of this profile). Symbol start indicated location of explosion.

Table 1. Densities of rocks in northern Vietnam as determined by Bui (1986) and this study.

\begin{tabular}{ccc}
\hline Rock type & Main lithofacies & Density $\boldsymbol{\rho}\left(\mathbf{g ~ c m}^{-\mathbf{3}}\right)$ \\
\hline Sedimentary rock & Sandstone, mudstone, limestone, shale, conglomerate & $2.00-2.78$ \\
Metamorphic rock & Gneiss, amphibolite, meta-sandstone & $2.40-3.05$ \\
Intermediate-acid magmatic rock & Granite, granodiorite, diorite, rhyolite, andesite & $2.39-2.63$ \\
Basic magmatic rock & Basalt, gabbro, peridotite & $2.51-2.87$ \\
Upper crust & - & $2.75-2.79$ \\
Lower crust & - & $2.82-2.88$ \\
Mantle & - & $3.14-3.21$ \\
\hline
\end{tabular}




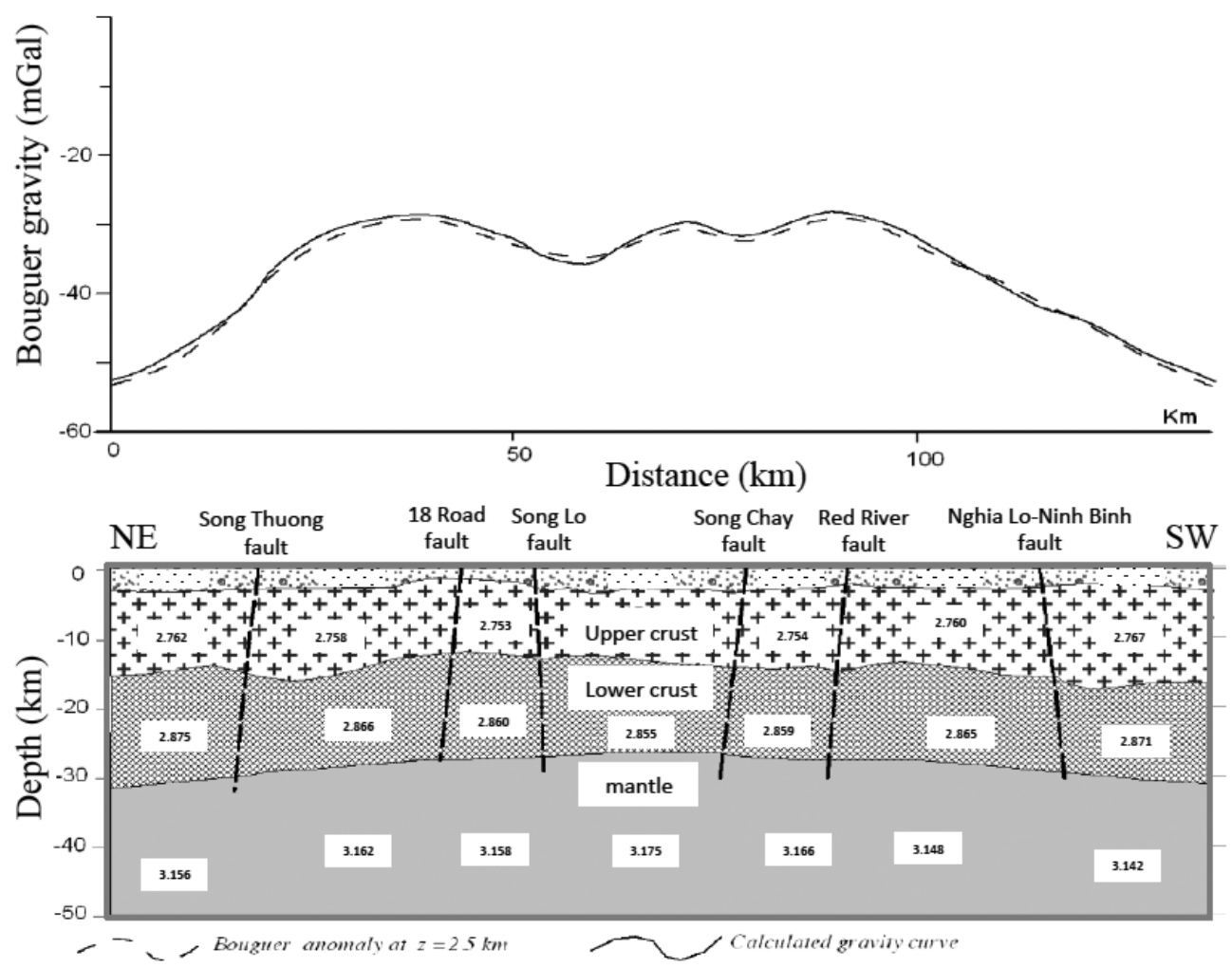

Fig. 10. Inverted crustal density model from gravity data along the northern seismic profile (T1). The crustal structure model of Fig. 8 was employed to fit the gravity observations, and densities within layers were estimated by data fitting.

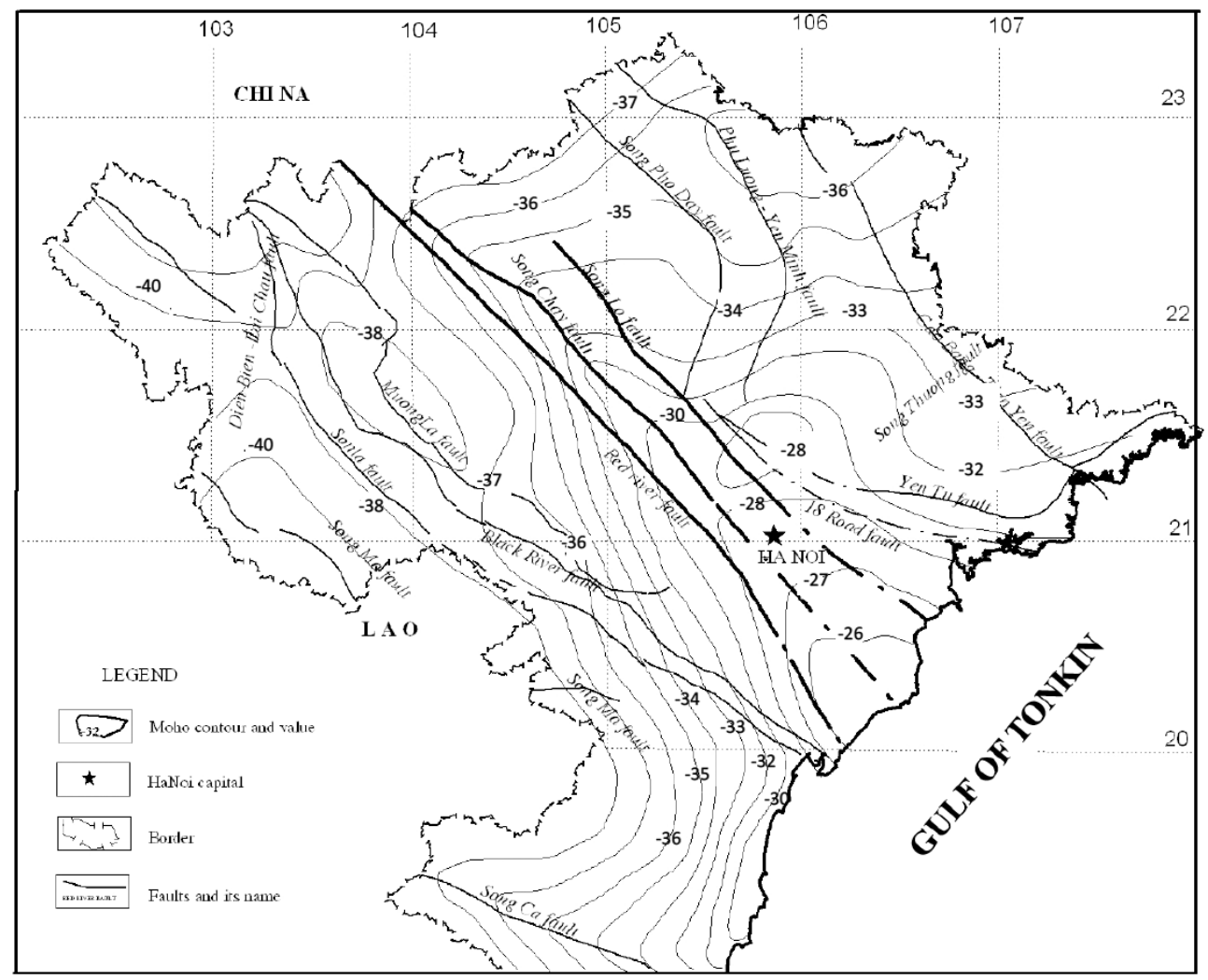

Fig. 11. Lateral variations in the depth of the Moho beneath northern Vietnam, integrated from 18 crustal structure profiles derived from 2D gravity inversion models. 
approximately $37 \mathrm{~km}$ in the Vietnam-China border area (Fig. 11). However, in the middle section of the region, we detected an uplifted structure where the depth of the Moho was smaller than $28 \mathrm{~km}$; this is located approximately $50 \mathrm{~km}$ north of Hanoi city. In the RRFZ, the Moho surface is characterized by an uplifted structure stretching along the entire segment of the fault system in northern Vietnam. The smallest crustal thickness smaller than $26 \mathrm{~km}$ was located in the area of the Hanoi basin.

The interface of the Conrad plane in northern Vietnam was obtained by calculations of this study as shown in Fig. 12. The plane presents a morphology that is substantially different from that in the Northeast and Southwest regions. Over half of the structures in the Northeast region are characterized by relatively isometric shapes and are distributed along a subparallel trend. In contrast with the Northeast region, the major structures in the Southwest region are extended in a NW-SE direction. Furthermore, several alternating positive and negative structures on the Conrad plane, occurring at several different scales, appear near the coastline. By comparison with the northern block, the southern block of the Northeast region shows a stronger uplift pattern.

These data on the Conrad represent the first analysis of this structure beneath northern Vietnam. In the following sections, more details of the features of this interface will be examined and correlated with the surficial geology.

\section{DISCUSSION}

\subsection{Lateral Variation of the Moho Interface}

Patterns of the Moho show regional differences between the Northeast and Southwest structural regions. The structure of the Moho in the Southwest region trends NW-SE in most areas, except in the southern end of the study region where the trend is submeridianal (Fig. 11). A region of relatively high horizontal gradients on the Moho in the Southwest region (as compared with gradients in the Northeast region) occurs from the middle to the south of the section. An elongated and uplifted Moho structure trending NW-SE and with a length larger than $100 \mathrm{~km}$ and a central depth smaller than $38 \mathrm{~km}$ occurs in the northern part of the Southwest region. Overall, the Moho identified in this study (Fig. 11) shows smoother features than those of the Conrad.

In the northern part of the Northeast structural region, the Moho trends subparallel to its surface geological structure direction and is gently dipping to the northeast in the northern-most part of the region. Thus, the depth of the Moho generally increases from coastal to mountainous areas, and increases more rapidly to the northwest. The depth of the Moho in the northwest corner of northern Vietnam is up to approximately $42 \mathrm{~km}$. Horizontal variations in the Moho across the RRFZ are represented as pronounced differences in the density and orientation of crustal thickness isolines.

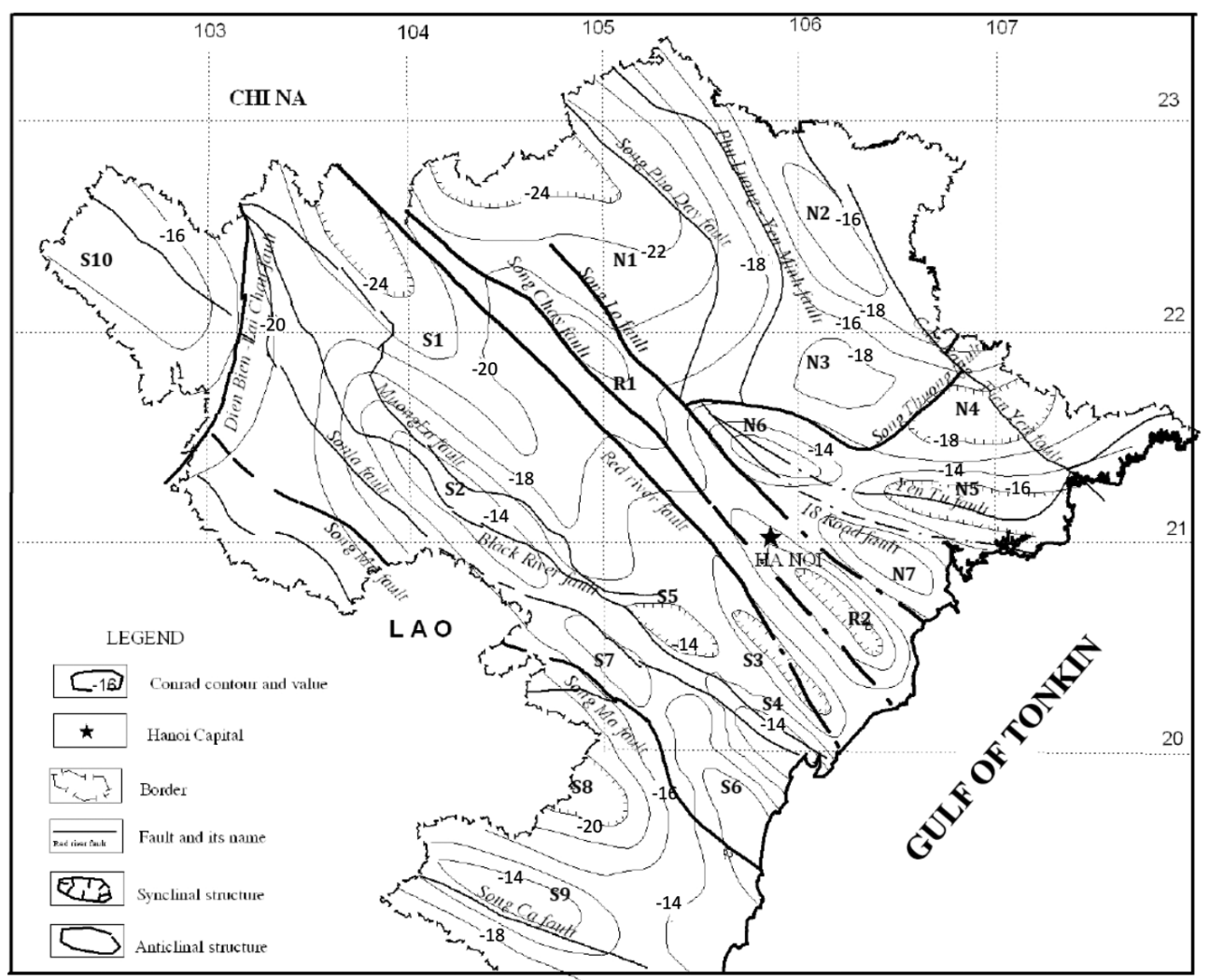

Fig. 12. Estimated depth of the 2D Conrad beneath northern Vietnam as determined by gravity inversion. 
Measurable uplift of the Moho in the area of the Hanoi basin and marked differences in the trends of structures in the Northeast and Southwest regions are signatures of crustal scale deformation along the Red River fault system in northern Vietnam. Analogous signs have been detected in patterns of deformation along other main tectonic faults, such as the submeridianal Dien Bien and Song Da faults, and arc-shaped faults in the northern part of the Northeast region.

\subsection{Lateral Variation of the Conrad Interface}

Based on the morphology of the Conrad, the Northeast region can be divided into two regional blocks separated by the arc-shaped subparallel Song Thuong fault, which is located in the middle of the region (Fig. 12). The largest structural unit located in the northern block is a region of subsidence; the depth of the Conrad in the center of the structure is larger than $24 \mathrm{~km}$. The unit is bounded to the northwest by the Song Chay fault and to the south and east by the arc-shaped Song Pho Day fault system (Lai et al. 2011), and the depression extends into the territory of China. This area correlates with the surficial location of the Song Chay metamorphic dome (Gilley et al. 2003; Searle 2006) and shown as SCMD in Fig. 2. Horizontal gradients on the Conrad are gentler on the northwestern side than on the eastern side of the unit.

Within the RRFZ, the Conrad is divided into two sections. In the northwest part of the RRFZ, the interface is slightly uplifted (R1 in Fig. 12) with a high point at a depth of $16 \mathrm{~km}$. The region of structure R1 contains the Day Nui Con Voi metamorphic complex, which outcrops along the RRSZ in northern Vietnam (Anczkiewicz et al. 2007; Yeh et al. 2008). In the southeast part of the RRFZ, the Conrad shows a deep depression trending NW-SE (R2, Fig. 12), with a depth in the center of the depression of larger than $20 \mathrm{~km}$. The Hanoi basin, with its thick sequence of Cenozoic sediments, is located above this depression.

In the Northeast region, located to the northeast of the RRFZ, the Conrad can be divided into northern and southern regions. In the northern region, the surface is smooth and dipping to the north (structure N1, Fig. 12); structures N2 and $\mathrm{N} 3$ are well correlated with patterns of moderate subsurface uplift. In addition, the locations of active faults in surface correlate with regional boundaries delineated by the morphology of the Conrad. In the southern region, two depressions (N4 and N5, Fig. 12) are located in the eastern part of the block, with depths to their centers larger than 18 and $16 \mathrm{~km}$, respectively. Two small uplifted structures (N6 and N7, Fig. 12) are located close to the Song Lo fault. These structures are located on the northeast periphery of the Hanoi basin, and are overlain by Quaternary-Neogene surficial sediments.

In the Southwest region, many structures on the Conrad are elongated in a NW-SE direction. Adjacent to and southwest of the Red River fault, a parallel feature of the Conrad extends for approximately $200 \mathrm{~km}$ (S1, Fig. 12). This area correlates with the surficial location of the Day Nui Con Voi complex (Cao and Dinh 1999; Dang 2003). Structure S2, located to the west of structure $\mathrm{S} 1$, is a significant uplifted structure with a NW-SE trending axis. Southeast of structures $\mathrm{S} 1$ and $\mathrm{S} 2$ and aligned in a NW-SE direction are five closed structures (S3 - S7), bounded by the Song Ma and Red River faults (Fig. 12). A linear structure is located parallel to the Red River fault (S3). Beside this structure, a couple of depressed and uplifted blocks (S4, S5) distributed. The locations of two structures (S6, S7) within the Song Ma uplifted block are consistent with the locations of subsurface structures and the morphology of the Conrad in this region. To the south of the Song Ma fault two structures (S8, S9) were detected on the Conrad. Structure S8 is a depression, with a depth of approximately $20 \mathrm{~km}$ at the Vietnam-Lao border; this structure is well correlated with the subsurface Phu Hoat uplift. Positive structure $\mathrm{S} 9$, with a depth smaller than $14 \mathrm{~km}$, is situated beneath the center of the subsurface Song Ca depression. A positive structure on the Conrad (S10), with a depth smaller than $16 \mathrm{~km}$ and located in the northwest corner of northern Vietnam, is bounded by the Dien Bien fault.

\subsection{Tectonic Implications}

The results of this study can be compared with two recently published reports on the depth of the Moho beneath northern Vietnam. The first, by Huang et al. (2013), describes local tomography, and the second, by Nguyen et al. (2013), describes the results of a regional receiver function analysis. Huang et al. (2013) provided the first regional 2D Moho variation map at low spatial resolutions, and Nguyen et al. (2013) provided better constrained Moho depths, but only at locations beneath 24 seismic stations used in their study. The present study, on the other hand, provides information on the Moho derived from uniform sampling and a high-resolution 2D variation map beneath northern Vietnam. The Moho depths determined in all three studies show slight differences across the Red River basin, and all indicate a greater depth for the Moho in the Southwest region. However, the results of Huang et al. (2013) show that the Moho is shallow beneath the northwestern mountainous region, as opposed to the results of Nguyen et al. (2013) and those of the present study. While the trends in the Moho depth determined by Nguyen et al. (2013) are similar to those determined in the present study, our Moho depths are systemically deeper (see Fig. 13). The discrepancies between the two studies can be attributed to differences in the values of crustal parameters used in the different models. However, the differences also point to possible limitations in the accuracy of the 3D crustal model determined by the present study, as inferences about crustal density using deep seismic data from only a limited range of structural zones may, given the geological complexity of northern Vietnam, compromise the results. Thus, in regions located farther from seismic profiles, the 
accuracies of 3D structures determined using the gravity inversion model might be reduced. Legendre et al. (2015) explore the Rayleigh-wave phase-velocity structure beneath northern Vietnam. Surface dispersion curves are inverted for both isotropic and azimuthally anisotropic Rayleigh-wave phase-velocity maps in the frequency range of $10-50 \mathrm{~s}$. Legendre et al. (2015) provided extra information of regional seismic anisotropy of the region. For isotropic velocity map, it provided a lateral variation of velocity pattern and consistent with the identified structure pattern of this study (Figs. 11 and 12). However, no crustal boundaries were identified from their results and to discuss uncertainty of boundaries. Furthermore, some uncertainties can be expected on account of terrain corrections for gravity observations in regions of complex mountainous topography. However, the consistent results of a greater depth for the Moho in the Southwest region of the northern Vietnam may link to the southeastern extension mechanism of the eastern Tibetan along the eastern Himalayan syntaxis.

The measurable thinning of the crust beneath the Hanoi basin, as revealed in this study and in other geophysical investigations, may be a major factor contributing to elevated geothermal gradients in the study region (Fig. 4). Crustal upwelling accompanying the extrusion of dense mantle material may compensate for rapid subsidence of the surface caused by rifting processes. In addition to the locally extended ellipsoidal anomaly inside the RRSZ, a moderate anomaly on the northern margins of the basin may have been generated by thermal fluids migrating along faults (Fig. 4). According to temperature estimates of the crust in the Hanoi basin, temperature gradients in the central part of the basin are higher than those in marginal areas (Dinh et al. 1994). On the uplifted section of the Moho located at a depth larger than $26 \mathrm{~km}$, the temperature is higher than $600^{\circ} \mathrm{C}$; meanwhile, in the marginal parts of the basin, where the Moho is horizontal and at a depth larger than $30 \mathrm{~km}$, the temperature is higher than $500^{\circ} \mathrm{C}$ (Dinh et al. 1994). Thus, the temperature distribution in the crust is well correlated with variations in crustal structure beneath the Hanoi basin. The regional high heat-flow and thin crust determined in this area were suggestive of a recent rifting process of the opening of the South China Sea (Mazur et al. 2012).

Low resistivity values were observed inside the RRFZ, from the shallow layer to the deep crust (Fig. 3). Low resistivity values at shallow depths are probably related to hydrologic saturation of deformed rocks within the RRSZ. In the deep crust, on the other hand, the low values may be attributed to the activity of geothermal fluids generated by enhanced heat flow from the mantle (Duchkov et al. 1992; Harder et al. 1995). For example, a low-resistivity zone on a section of the Song Lo fault (located at the area of measurement point DA2 of Fig. 3) was detected that can be associated with a region of relatively high heat-flow anomaly and in a smaller area where heat flow exceeded $70 \mathrm{mWm}^{-2}$ (Fig. 4).
An unusual low-resistivity area observed in the upper mantle in the RRSZ (less than 200 Ohmm in Fig. 3) may correspond to an enhanced ductility. Link to the crustal profile along the seismic line (Fig. 10) and determined entire Moho interface of the northern Vietnam (Fig. 11), the lateral variation of the Moho depths across the RRFZ has no direct relation with the surface faults. It may indicate that the RRFZ developed within crust and remained a crustal fault.

\subsection{Earthquake Hazard Issues}

Comparing to major tectonic active regions of the world, Vietnam is ranked as a low-seismicity region by its self-evaluation (Nguyen 2010). However, present-day seismic activity has included a series of moderate earthquakes, some of which have caused remarkable damage. Historically, moderate earthquakes have been reported most frequently in the vicinity of active regional faults (Nguyen 2010). According to previous studies, nearly $90 \%$ of the earthquakes in the region have been located in northern Vietnam, and among them, a large proportion are concentrated at shallow depths in the Northwest structural region (Huang et al. 2009; Nguyen 2010). The relationship between seismic activity and the temperature distribution in the crust in northern Vietnam should be addressed in future studies. Furthermore, according to the integrated geophysical investigations of the present study, the RRFZ is a major active fault of this region. However, until now, evidence regardless stress conditions in the RRFZ. It can be either strain free or fault lack saturations. Further studies are therefore required to resolve important questions about the nature of seismic hazards in this region.

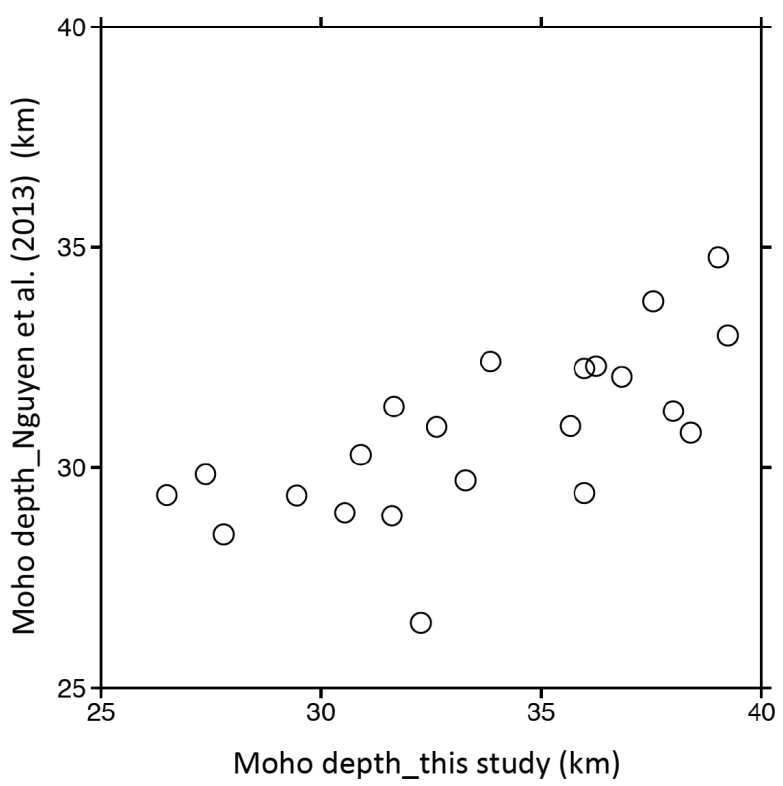

Fig. 13. The relationship of Moho depth as determined by Nguyen et al. (2013) at 24 analyzed seismic stations (vertical axis) and that selected from Fig. 11 of this study (horizontal axis). 
The high population density of Vietnam necessitates effective and sustainable land-use pattern. Geological hazard assessments derived from scientific research studies during the last decade have still not satisfied the increasing demand for effective land-use planning and hazard mitigation in relation to ongoing economic development. This study contributes information to these issues, based on recent geophysical investigations related to the southern segment of the RRSZ in northern Vietnam. The structures on the Moho and Conrad determined in this study provide the outlines of a 3D crustal model of northern Vietnam, which could be used for modeling seismic wave propagation and predicting ground motions related to seismic events also.

\section{CONCLUSIONS}

In this study, the entire crustal structure of northern Vietnam was constructed by inverting gravity data with constrains by regional crustal density values. Crustal densities were determined by fitting gravity profiles along two previously analyzed seismic profiles. Analyzed results indicate that the RRFZ is the boundary between two regional crustal blocks with slight differences in density and Moho depth. The newly determined Moho suggests a more stable regime in the northeast region relative to that in the Northwest region. The morphology of the Moho is well correlated with major geological boundary faults in the region. Detailed zonation of the Conrad indicates that surface variations are well correlated with major subsurface geological structures in northern Vietnam. As compared to previous magnetotelluric and heat-flow observations, the detected low resistivity in the uppermost mantle beneath the Hanoi basin shows a good correlation with a high heat-flow anomaly and thin crust and link to the response of the opening of the South China Sea.

Acknowledgements We express our appreciation to the Incorporated Research Institutions for Seismology (IRIS), Program for Array Seismic Studies of the Continental Lithosphere (PASSCAL), United States, for field instrument support, and the staff of the Vietnam Academy of Science and Technology (VAST) for the collection of data used in this study. We also thank Dr. H. H. Huang, Prof. M. W. Yeh, and T. Y. Lee for helpful comments and valuable discussions. This study was funded by the Vietnam National Foundation for Science and Technology Development (NAFOSTED), grant 105.01.24.09, by the National Science Council, Taiwan, grant NSC101-2116-M-001-033, and by the Vietnam Academy of Sciences and Technology, grant VAST05.01/15-16.

\section{REFERENCES}

Allen, C. R., A. R. Gillespie, Y. Han, K. E. Sieh, B. Zhang, and C. Zhu, 1984: Red River and associated faults, Yunnan Province, China: Quaternary geology, slip rates, and seismic hazard. Geol. Soc. Am. Bull., 95, 686-700, doi: 10.1130/0016-7606(1984)95<686:RRA $\mathrm{AFY}>2.0 . \mathrm{CO} ; 2 .[\mathrm{Link}]$

Anczkiewicz, R., G. Viola, O. Müntener, M. F. Thirlwall, I. M. Villa, and N. Q. Quong, 2007: Structure and shearing conditions in the Day Nui Con Voi massif: Implications for the evolution of the Red River shear zone in northern Vietnam. Tectonics, 26, TC2002, doi: 10.1029/2006TC001972. [Link]

Bui, C. X., 1986: The density parameter of the rocks and ore in Vietnam (in Vietnamese). Report of Vietnam Geological Survey, 46 pp. (in Vietnamese)

Bui, Q. C., 1982: Structural characteristics and tectonics of the Vietnam territory derived from Geophysical data. J. Geol., 154, 9-12. (in Vietnamese)

Bui, Q. C., 1983: About the new results of the deep structural study of territory of Vietnam. Vietnam Journal of Earth Sciences, 5, 27-40. (in Vietnamese)

Busby, J. P., 1987: An interactive FORTRAN 77 program using GKS graphics for 2.5 D modeling of gravity and magnetic data. Comput. Geosci., 13, 639-644, doi: 10.1016/0098-3004(87)90032-X. [Link]

Cao, T. D., 1985: The method interpret gravity data to research the Earth's crust of northern Vietnam. Proceedings of the Second Vietnam Scientific Conference on Geology, Vietnam Geological Survey, Hanoi, 27-40.

Cao, T. D. and T. V. Dinh, 1999: Main crustal feature of the crust in Vietnam and adjancent area on the basic of gravity data. Proceedings of the Fourth Vietnam National Conference on Marine Science and Technology, Hanoi, 854-863. (in Vietnamese)

Chung, S. L., T. Y. Lee, C. H. Lo, P. L. Wang, C. Y. Chen, N. T. Yem, T. T. Hoa, and W. Genyao, 1997: Intraplate extension prior to continental extrusion along the Ailao Shan-Red River shear zone. Geology, 25, 311314, doi: 10.1130/0091-7613(1997)025<0311:IEPTC E>2.3.CO;2. [Link]

Dang, H. T., 2003: Study of structural characteristics and seismotectonic zonation in North Vietnam. Ph.D. Thesis, Institute of Geophysics, Vietnam Academy of Science and Technology, Hanoi, Vietnam. (in Vietnamese)

Department of Geology and Minerals of Vietnam, 1995: Bouguer Gravity Anomaly Map for Northern Vietnam, Scale 1:500,000, Northern Geological Mapping Division, Hanoi, Vietnam.

Dinh, T. V., 2010: Study of the Earth Crustal structures of Northern Vietnam by using the deep seismic, magnetotelluric investigations and gravity data (eds), Vietnam National Science Project: KC.08.06/06/10: Outcome Report - 8/2010.

Dinh, T. V., A. D. Duchkov, Y. T. Nguyen, S. Harder, and B. V. Trinh, 1994: The first geothermal model and temperature distribution in the lithosphere of the Hanoi basin. Vietnam Journal of Earth Sciences, 16, 49-58. 
(in Vietnamese)

Dinh, T. V., S. Harder, B. V. Trinh, T. V. Doan, P. H. Lai, V. A. Tran, and Q. H. Nguyen, 2009: Preliminary results on the study of the earth crustal structure in Northern Vietnam by deep seismic data analysis. Vietnam Journal of Earth Sciences, 31, 289-298. (in Vietnamese)

Dinh, T. V., S. Harder, V. N. Pham, B. V. Trinh, P. H. Lai, T. V. Doan, V. A. Tran, and Q. H. Nguyen, 2010: The earth's crustal structures of Northern Vietnam based on the combined analysis of gravity data and deep seismic investigation. Proceedings of the Scientific Conference Celebrated 35 Years of Vietnam Academy of Science and Technology 1975 - 2010, Science and Technology, Publishing House, Hanoi, 80-89. (in Vietnamese)

Dinh, T. V., S. Harder, V. N. Pham, B. V. Trinh, P. H. Lai, T. V. Doan, V. A. Tran, and Q.H. Nguyen, 2011: The study of the crustal structures by using the seismic refraction data collected along the two profiles of deep seismic investigations in northern Vietnam. Vietnam Journal of Earth Sciences, 33, 185-195. (in Vietnamese)

Doan, T. V. and T. V. Dinh, 2003: Electrical anisotropy of conductive structure in the Earth's crust of the Red River fault zone. Vietnam Journal of Earth Sciences, 25, 117-122. (in Vietnamese)

Doan, T. V., T. V. Dinh, and Y. T. Nguyen, 2001: Deep structure feature of the Red River fault zone and its geodynamic implication from magnetotelluric data. Vietnam J. Geol., 267, 21-28. (in Vietnamese)

Doan, T. V., T. V. Dinh, B. V. Trinh, and G. H. Pham, 2010: The Geothermal resources and potential in the Hanoi basin, Vietnam. Proceedings of World Geothermal Congress 2010 Bali, Indonesia, 5 pp.

Duchkov, A. D., Y. T. Nguyen, T. V. Dinh, and B. V. Trinh, 1992: First estimations of heat flow in North Vietnam. J. Geol. Geophys., 33, 92-96. (in Russian)

England, P. and G. Houseman, 1986: Finite strain calculations of continental deformation: 2. Comparison with the India-Asia Collision Zone. J. Geophys. Res., 91, 3664-3676, doi: 10.1029/jb091ib03p03664. [Link]

Gilley, L. D., T. M. Harrison, P. H. Leloup, F. J. Ryerson, O. M. Lovera, and J. H. Wang, 2003: Direct dating of left-lateral deformation along the Red River shear zone, China and Vietnam. J. Geophys. Res., 108, doi: 10.1029/2001JB001726. [Link]

Harder, S. and V. T. Dinh, 2011: Collecting deep seismic data in densely populated Vietnam. Eos, Trans., AGU, 92, 21-22, doi: 10.1029/2011EO030001. [Link]

Harder, S., T. V. Dinh, Y. T. Nguyen, B. V. Trinh, V. G. Nguyen, J. Mauri, A. Fisher, R. McCabe, and M. F. J. Flower, 1995: Preliminary heat flow results from the Hanoi basin, Vietnam. In: Gupta, M. L. and M. Yamano (Eds.), Terrestrial Heat Flow and Geothermal Energy in Asia, Oxford \& IBH Publishing CO, PVT LTD, New Delhi, India, 163-172.
Huang, B.-S., T. S. Le, C.-C. Liu, D. V. Toan, W.-G. Huang, Y.-M. Wu, Y.-G. Chen, and W.-Y. Chang, 2009: Portable broadband seismic network in Vietnam for investigating tectonic deformation, the earth's interior, and early-warning systems for earthquakes and tsunamis. J. Asian Earth Sci., 36, 110-118, doi: 10.1016/j.jseaes.2009.02.012. [Link]

Huang, H. H., Z. J. Xu, Y. M. Wu, X. Song, B. S. Huang, and L. M. Nguyen, 2013: First local seismic tomography for Red River shear zone, northern Vietnam: Stepwise inversion employing crustal $\mathrm{P}$ and $\mathrm{Pn}$ waves. Tectonophysics, 584, 230-239, doi: 10.1016/j.tecto.2012.03.030. [Link]

Jolivet, L., O. Beyssac, B. Goffé, D. Avigad, C. Lepvrier, H. Maluski, and T. T. Thang, 2001: Oligo-Miocene midcrustal subhorizontal shear zone in Indochina. Tectonics, 20, 46-57, doi: 10.1029/2000TC900021. [Link]

Lai, H. P., V. T. Dinh, and A. V. Tran, 2011: Fault incline determination of main active faults in the territory of North Vietnam by maximum horizontal gradient calculation of gravity anomalies. Vietnam Journal of Earth Sciences, 33, 554-560. (in Vietnamese)

Le, H. M., T. S. Vo, C. T. Nguyen, T. V. Nguyen, D. X. Nguyen, G. Marquis, and V. T. Tran, 2008: Two dimensional electrical structure of the Son La fault zone on the results of magnetotelluric sounding. Vietnam Journal of Earth Sciences, 30, 491-502. (in Vietnamese)

Le, H. M., V. N. Pham, D. Boyer, N. T. Nguyen, T. T. Le, V. Q. Nguyen, and G. Marquis, 2009: Investigation on the deep geoelectric structure of the Lai Chau-Dien Bien fault zone by magnetotelluric sounding. J. Geol., 11-21. (in Vietnamese)

Lee, T.-Y. and L. A. Lawver, 1995: Cenozoic plate reconstruction of southeast Asia. Tectonophysics, 251, 85138, doi: 10.1016/0040-1951(95)00023-2. [Link]

Legendre, C. P., L. Zhao, W. G. Huang, and B. S. Huang, 2015: Anisotropic Rayleigh-wave phase velocities beneath northern Vietnam. Earth Planets Space, 67, doi: 10.1186/s40623-015-0193-3. [Link]

Leloup, P. H., R. Lacassin, P. Tapponnier, U. Schärer, D. Zhong, X. Liu, L. Zhang, S. Ji, and P. T. Trinh, 1995: The Ailao Shan-Red River shear zone (Yunnan, China), Tertiary transform boundary of Indochina. Tectonophysics, 251, 3-84, doi: 10.1016/0040-1951(95)000704. [Link]

Leloup, P. H., P. Tapponnier, R. Lacassin, and M. P. Searle, 2007: Discussion on the role of the Red River shear zone, Yunnan and Vietnam, in the continental extrusion of SE Asia Journal, Vol. 163, 2006, 1025-1036. J. Geol. Soc., 164, 1253-1260, doi: 10.1144/001676492007-065. [Link]

Mazur, S., C. Green, M. G. Stewart, J. M. Whittaker, S. Williams, and R. Bouatmani, 2012: Displacement along the Red River Fault constrained by extension estimates 
and plate reconstructions. Tectonics, $\mathbf{3 1}$, TC5008, doi: 10.1029/2012TC003174. [Link]

McMechan, G. A., R. W. Clayton, and W. D. Mooney, 1982: Application of wave field continuation to the inversion of refraction data. J. Geophys. Res., 87, 927-935, doi: 10.1029/JB087iB02p00927. [Link]

Nguyen, H. V. and V. Q. Hoang, 2001: Moving characteristics of the Dien Bien Phu fault zone during Cenozoic. J. Geology, Series A, 65-77. (in Vietnamese)

Nguyen, H. V., Y. T. Nguyen, and V. Q. Hoang, 1996: Characteristics of the main northwest-southeast trending tectonic faults in Northern Vietnam region. In: Nguyen, Y. T. (Ed.), Geology - Resources, Science \& Technics Publishing House, Hanoi, Vietnam, Vol. 1, 47-58. (in Vietnamese)

Nguyen, T. D., 1996a: Characteristics of strike-slip movement of the Red River fault system in Cenozoic time. In: Nguyen, Y. T. (Ed.), Geology - Resources, Science \& Technics Publishing House, Hanoi, Vol. 2, 36-41. (in Vietnamese)

Nguyen, T. K. T., 1996b: Underground water exploration in Cuu Long and Red River deltas using magnetotelluric and geoelectrical methods (eds). Vietnam National Basic Science Project: Outcome Report-1996, 446 pp.

Nguyen, V. D., B. S. Huang, T. S. Le, V. T. Dinh, L. Zhu, and K. L. Wen, 2013: Constraints on the crustal structure of northern Vietnam based on analysis of teleseismic converted waves. Tectonophysics, 601, 87-97, doi: 10.1016/j.tecto.2013.04.031. [Link]

Nguyen, X. D., 2010: Earthquakes in territory of Vietnam. In: Nguyen, Y. T. and A. K. Tokarski (Eds.), Cenozoic Dynamics of northern Vietnam, Science and Technology Publishing House, Hanoi, 165-177.

Nguyen, Y. T., 1991: The main characteristics of geodynamics in the territory of North Vietnam. In: Nguyen, Y. T. (Ed.), Geology - Resources, Science \& Technics Publishing House, Hanoi, 19-23. (in Vietnamese)

Pham, V. N., D. Boyer, V. G. Nguyen, and T. K. T. Nguyen, 1995: Electrical properties and deep structure of the Red River fault zone in North Vietnam from magnetotelluric sounding results. C. R. Acad. Sci. Paris, 320, 181-187.

Phan, T. T., N. V. Liem, N. V. Huong, H. Q. Vinh, B. V. Thom, B. T. Thao, M. T. Tan, and H. Ng, 2012: Late Quaternary tectonics and seismotectonics along the Red River fault zone, North Vietnam. Earth Sci. Rev., 114, 224-235.

Replumaz, A., R. Lacassin, P. Tapponnier, and P. H. Leloup, 2001: Large river offsets and Plio-Quaternary dextral slip rate on the Red River fault (Yunnan, China). J.Geophys. Res., 106, 819-836, doi: 10.1029/2000JB900135. [Link]

Searle, M. P., 2006: Role of the Red River Shear zone, Yunnan and Vietnam, in the continental extrusion of SE Asia.J.Geol.Soc., 163, 1025-1036, doi: 10.1144/0016-
76492005-144. [Link]

Tapponnier, P. and P. Molnar, 1977: Active faulting and tectonics in China. J. Geophys. Res., 82, 2905-2930, doi: 10.1029/JB082i020p02905. [Link]

Tapponnier, P., G. Peltzer, A. Y. Le Dain, R. Armijo, and P. Cobbold, 1982: Propagating extrusion tectonics in Asia: New insights from simple experiments with plasticine. Geology, 10, 611-616, doi: 10.1130/0091-7613( 1982) $10<611$ :PETIAN>2.0.CO;2. [Link]

Tapponnier, P., G. Peltzer, and R. Armijo, 1986: On the mechanics of the collision between India and Asia. Geol. Soc. Lond. Spec. Publ., 19, 113-157, doi: 10.1144/ GSL.SP.1986.019.01.07. [Link]

Thanassoulas, C., G. A. Tselentis, and K. Dimitriadis, 1987: Gravity inversion of a fault by Marquardt's method. Comput. Geosci., 13, 399-404, doi: 10.1016/00983004(87)90012-4. [Link]

Tran, T. H., A. E. Izokh, G. V. Polyakov, A. S. Borisenko, T. A. Tran, P. A. Balykin, T. P. Ngo, S. N. Rudnev, V. V. Vu, and A. N. Bui, 2008: Permo-Triassic magmatism and metallogeny of Northern Vietnam in relation to the Emeishan plume. Russ. Geol. Geophys., 49, 480-491.

Tran, T. V. and C. D. Van, 1996: Horizontal displacement of the earth crust in the Red River fault during Pliocene-Quaternary. In: Nguyen, Y. T. (Ed.), Geology - Resources, Science \& Technics Publishing House, Hanoi, Vol. 1, 33-46. (in Vietnamese)

Tran, T. V. and T. D. Van, 2006: Pliocene-Quaternary tectonics of the Northwestern Region of Vietnam. Vietnam Journal of Earth Sciences, 28, 86-99. (in Vietnamese)

Vu, C. V., 1996: Active faults during Cenozoic time in Northeastern Vietnam. In: Nguyen, Y. T. (Ed.), Geology - Resources, Science \& Technics Publishing House, Hanoi, 22-32. (in Vietnamese)

Won, I. J. and M. Bevis, 1987: Computing the gravitational and magnetic anomalies due to a polygon: Algorithms and Fortran subroutines. Geophysics, 52, 232-238, doi: 10.1190/1.1442298. [Link]

Wu, H. H., Y. B. Tsai, T. Y. Lee, C. H. Lo, C. H. Hsieh, and D. V. Toan, 2004: 3-D shear wave velocity structure of the crust and upper mantle in South China Sea and its surrounding regions by surface wave dispersion analysis. Mar. Geophys. Res., 25, 5-27, doi: 10.1007/ s11001-005-0730-8. [Link]

Yeh, M. W., T. Y. Lee, C. H. Lo, S. L. Chung, C. Y. Lan, and T. T. Anh, 2008: Structural evolution of the Day Nui Con Voi metamorphic complex: Implications on the development of the Red River Shear Zone, Northern Vietnam. J. Struct. Geol., 30, 1540-1553, doi: 10.1016/j.jsg.2008.08.007. [Link]

Zelt, C. A., and R. B. Smith, 1992: Seismic traveltime inversion for 2-D crustal velocity structure. Geophys. J. Int., 108, 16-34, doi: 10.1111/j.1365-246x.1992.tb00836.x. [Link] 